\title{
"Meninos" e "Professoras"? Pragmática social numa instituição de cuidado de deficientes
}

\author{
Children" and "Teachers"? Social pragmatics \\ in a disabled care institution
}

\author{
Ubiratan Garcia VIEIRA \\ (Universidade Federal da Fronteira Sul - UFFS, Campus Chapecó)
}

\section{RESUMO}

Apoiado em teses de Kanavillil Rajagopalan, para quem toda representação é política, pois é uma escolha dentre representações possiveis, e de Howard Becker, para quem toda representação é adequada a determinadas condições sociais de fazer e uso, apresento uma reflexão sobre os usos das designações "meninos" e "professoras", observados durante as atividades de extensão realizadas numa instituição de cuidado de pessoas deficientes. Esta instituição não é um espaço escolar, mas em vez de procurar responder se essas designações correspondem ou não à "realidade", procurei entender a que realidade corresponde o uso dessas designações. Concluo que os usos das designações "meninos" e "professoras" evidenciam a posição marginal que a instituição ocupa no sistema municipal de ensino e colocam para os envolvidos, incluindo a equipe de extensão, um posicionamento quanto aos usos mais adequados ao contexto.

Palavras-chave: Pragmática social; educação; pessoas com deficiência; designação. 


\section{ABSTRACT}

Supported by Kanavillil Rajagopalan's theses on the political character of every representation, for there are choices being made, and by Howard Becker's theses on the appropriateness of every representation to certain social conditions of making and use, I present a reflection on the uses of the terms "kids" and "teachers", observed during extension activities held in a care institution for disabled people. This institution is not a school, but instead of seeking to answer whether or not these designations correspond to "reality," I sought to understand the reality that corresponds the use of these designations. I conclude that the uses of the designations "kids" and "teachers" both show the marginal position that the institution holds in the municipal education system and demand, for those involved, including the extension team, the need to decide wich are the most appropriate terms to use in this context.

Key-words: Societal pragmatics; education; people with disabilities; naming.

\section{Introdução}

A emancipação como ponto de partida da pragmática social coloca desafios à pesquisa dos usos da linguagem, sobretudo nos usos de designações, uma vez que não é possível não utilizá-las quaisquer que sejam as circunstâncias e os envolvidos no contexto. Embora as reflexões sobre a pragmática social como uma perspectiva para o uso da linguagem - inclusive na pesquisa e na apresentação dos seus resultados - se desenvolvam atualmente tendo em vista o ensino de línguas, o foco no uso de designações amplia o escopo da pesquisa para outros contextos. Um exemplo é a presente pesquisa, em que aproximo a pragmática social dos estudos sobre deficiência, particularmente aqueles do tipo etnográfica (cf.: Davis 2006).

Neste artigo, apresento algumas reflexões sobre o uso dos termos "meninos" e "professoras" no contexto de um projeto de extensão com interface com pesquisa ${ }^{1}$ realizada em 2012 e 2013 numa instituição de

1. Projeto realizado com o apoio da Fundação de Amparo à Pesquisa de Minas Gerais UFOP. Coordenado por mim e pela Profa. Dra. Mônica Farid Rhame (DEEDU/UFOP). 
cuidado de pessoas com deficiência em Mariana (MG), uma cidade histórica, de mais de cinquenta mil habitantes. Dentre as atividades que desenvolvemos com a colaboração de estudantes de pedagogia e serviço social, destaco a realização de uma gincana com equipes mistas formadas por estudantes universitários e usuários e usuárias da instituição, e uma passeata realizada num sábado com a participação de mais de setenta pessoas, ocupando as ruas da cidade pelo direito à acessibilidade. As reflexões que apresento se referem à primeira parte das atividades com duração de um semestre, que consistiu em visitas periódicas à instituição com o objetivo de se dar a conhecer a vida cotidiana naquele espaço, seguindo pressupostos da pesquisa do tipo etnográfica. Nesse convívio inicial encontramos o uso dos termos "meninos" e "professoras", o que não seria de estranhar não fosse o caso de a instituição não ser uma escola. Foi justamente esse aparente paradoxo representacional que motivou as reflexões que apresento a seguir.

\section{Pragmática social e extensão universitária}

Se a pragmática estuda o uso da linguagem e esse uso se dá nas relações sociais concretas, o que sustenta a expressão "pragmática social"? A partir da leitura dos artigos intitulados "Aspectos sociais da pragmática" de Rajagopalan (2010) e "How to do good things with words" de Mey (1994), que discutem essa perspectiva sobre a linguagem, podemos responder que certa concepção positivista da linguística e uma certa concepção solipsista de pessoa tomou conta das práticas da pesquisa pragmática nos seus primeiros passos no início dos anos de 1970, trazendo como efeito uma crescente angústia de seus precursores, sobretudo Jacob Mey, levando-os a propor uma pragmática politizada, que não seja um componente da linguística, mas uma perspectiva sobre a linguagem, definida pela vida social.

O termo "pragmática" permitiu um lugar na concepção tripartite da ciência da linguagem proposta por Carnap e, assim, permitiu procurar no formalismo da pesquisa semântica e sintática um amparo para a pesquisa sobre o uso da linguagem. Por outro lado, a incorporação das teses de Grice levou a pesquisa pragmática a adotar como pressuposto a abstração da intencionalidade do falante. Vale lembrar que esse pressuposto está amparado numa concepção de sociedade que não reconhece as pessoas como seres sociais, isto é, em relação umas 
com as outras, mas como indivíduos isolados. Com o apelo à figura do indivíduo isolado, a pesquisa pragmática se atrela à psicologia cognitiva e à filosofia da mente e toma para si a importância atribuída pelo discurso hegemônico à produção de conhecimento linguístico que abstrai a linguagem de sua realidade social. Já a pragmática social, a despeito de sua proximidade com a sociologia e a antropologia, é apresentada por Mey (1994 2010) não como uma ciência social, mas como uma ciência politizada da linguagem que leva a sério o fato de a linguagem ser uma realidade "socialmente constituída". Vale destacar que esse convite ao reconhecimento da constituição social da linguagem foi feito por Dell Hymes (1984), desde suas primeiras críticas à proposta de Chomsky para a linguística, ainda em 1966.

A consciência de que a linguagem é socialmente constituída coloca para pesquisadoras e pesquisadores do uso da linguagem a necessidade de escolherem entre "cognitivismo" e "societalismo" (Rajagopalan, 2010). Uma escolha não de natureza "teórica", opondo aspectos cognitivos e sociais do uso da linguagem, mas sim "política", opondo os domínios privados e públicos da prática da pesquisa (Rajagopalan ,1999: 142), ou melhor, individualismo e coletivismo (Rajagopalan, 2010). A escolha entre uma e outra perspectiva "implica opiniões conflitantes sobre a natureza do ser humano, sobre a sociedade e a relação entre os dois" (Rajagopalan, 2010: 43). Sendo uma escolha política, permeia não somente as escolhas feitas nas atividades de pesquisa, mas também as escolhas feitas em todas as atividades da vida social. Em outras palavras, a escolha por uma pragmática social não implica escolhas para o estudo do uso da linguagem, mas sim de uso da linguagem, nas atividades de pesquisa e em outras atividades da vida social (Hymes, 1984). Tomemos por exemplo o uso de designações. Em que situações da vida social nos abstemos de escolher uma designação dentre outras disponíveis? É possível pesquisar a ancoragem social da escolha das designações que os outros fazem e ignorar o fato de que as nossas próprias escolhas linguísticas são já ancoradas socialmente? Essas questões colocam para a pesquisa pragmática o problema da forma como se participa da vida social e, tendo como ponto de partida a emancipação, a consciência dessa forma de participação.

A oposição entre cognitivismo/domínio privado/individualismo e societalismo/domínio público/coletivismo permite à pesquisadora 
se tornar consciente da forma como participa da realidade que estuda. Trata-se ou de manter distância da realidade social (individualismo), ou de intervir diretamente nessa realidade (coletivismo). No segundo caso, precisamos considerar como pontos de partida a emancipação (Mey, 2010). Isto é, precisamos reconhecer que as pessoas com as quais lidamos são responsáveis pelo que dizem, têm as suas próprias vontades e necessidades e que, portanto, precisamos reconhecer as implicações de nossa intervenção na vida das pessoas, antecipando as consequências de nossas ações.

\section{Um lugar para chamar de escola por certas pessoas em certas circunstâncias}

A Comunidade da Figueira estava localizada num bairro central, porém pouco visível, da cidade, no qual um grupo de cinquenta pessoas com deficiência encontravam um lugar de convívio que atendia as suas necessidades de atenção e cuidado. $\mathrm{O}$ nome se referia à parábola bíblica da figueira estéril, porém "a Comunidade da Figueira da frutos" para as pessoas que ali conviviam. Ativa desde 1990, a Comunidade surgiu pelo suporte de um conhecido e querido arcebispo da cidade de Mariana, Dom Luciano, já falecido. Dado seu caráter filantrópico e religioso, a Figueira constitui um indício tardio de um tipo de cuidado de pessoas com deficiência hegemônico no Brasil desde o império até o final dos anos de 1980 (Cf.: Vieira, 2013). Quando da pesquisa, a Figueira estava á vinculada administrativamente à Fundação Marianense de Educação, mantenedora de ações educacionais e assistenciais vinculadas à Arquidiocese de Mariana. Seus recursos, que eram muito escassos, advinham da prefeitura municipal, através de convênios, mas também de doações particulares e de projetos em parceria com as mineradoras que atuam no município.

A equipe responsável pelo espaço era composta por uma diretora, uma secretária, cinco monitoras, uma psicóloga e uma professora, além do motorista e de uma equipe de limpeza e apoio de cinco pessoas. Fisioterapeutas e fonoaudiólogas da Secretaria da Saúde do município realizavam o atendimento de usuários e usuárias duas vezes por semana na parte da manhã. As monitoras era, responsáveis, cada uma delas, por um grupo de até oito pessoas. Quatro turmas se distribuíam em 
salas pequenas ao redor de mesas grandes, onde realizavam atividades de artesanato e desenho. Uma quinta turma se encontrava numa sala maior. A monitora dessa turma cuidava da higiene, entretenimento e alimentação do grupo. É principalmente a esse grupo que se dedicavam as atividades de fisioterapia. O grupo era chamado de "turma da Joana", o nome da monitora responsável (os nomes de pessoas da Comunidade são fictícios) e a sala de "sala de estimulação", tendo recebido já o nome de "sala dos anjinhos". Um aluno dessa turma preferia ficar deitado boa parte do tempo e dois ficavam em cadeiras de rodas à disposição da iniciativa de pessoas designadas para empurrá-las. Uma característica geral dessa turma era a comunicação gestual. O grupo se encontrava segregado do convívio com os demais usuários e usuárias da Comunidade. Durante a refeição e os descansos, saiam das salas para ficar em ambientes externos no próprio espaço da Comunidade. Não compartilhavam dos mesmos espaços e momentos de convívio.

Embora formalmente o público da Comunidade da Figueira fosse caracterizado como sendo o de pessoas com "deficiência múltipla", "deficiência física" e/ou "mental", é muito fácil perceber que, na realidade, as usuárias e usuários da Comunidade diferiam bastante no que diz respeito às suas "condições de saúde" e ao seu "desempenho na participação das situações da vida” (WHO 2002, cf. Diniz Medeiros e Squinca 2007). Assim, além do grande grupo de usuários e usuárias que praticavam artesanato e desenho com supervisão de monitoras, e da "turma da Joana", existia ainda outro grupo, todos homens de mais de trinta anos, que não ficavam sob a responsabilidade das monitoras nem ficavam, necessariamente, nas salas. Faziam serviços de marcenaria necessários à elaboração do artesanato, horta com produção utilizada nas refeições, ou auxiliavam o trabalho das monitoras, da diretora e da secretária, sobretudo, no caso, auxiliavam outros colegas na higiene pessoal e refeições, mas também digitando documentos. Um deles se dispôs voluntariamente a ser o vigia da Comunidade, recepcionando quem chega, de posse do controle remoto do portão. Outro deles tinha conseguido por iniciativa própria uma cadeira de rodas motorizada e já havia denunciado na procuradoria do município a falta de acessibilidade da cidade.

As atividades na Comunidade aconteciam de manhã e de tarde durante a semana. Mais da metade dos usuários e das usuárias frequentavam a comunidade há mais de dez anos. A maioria adulta. Três delas 
são idosas e apenas uma criança frequentava a instituição. No caso das responsáveis pela instituição, quatro delas trabalhavam na Comunidade desde seu início e outras duas há mais de cinco anos. Apenas a diretora tinha menos de dois anos de trabalho na Comunidade.

O que permite compreender a singularidade da Comunidade são os laços que havia de amizade e de parentesco envolvendo as usuárias, os usuários e as responsáveis. Laços construídos ao longo dos mais de 20 anos de seu funcionamento, condicionados pelo momento e forma de inserção e pelas experiências de afeto e desavença ali vividas. A relevância íntima do trabalho estava muito bem marcada pelo envolvimento da vida familiar e pessoal na dinâmica organizacional, evidenciado pela realização de festas de aniversário, casamento e natal nesse espaço. As usuárias e os usuários também compartilhavam desses fortes laços afetivos entre si. A amizade entre usuárias do mesmo gênero e a paquera entre aqueles de gênero diferente é comum no interior da Comunidade. Todas e todos, responsáveis, usuárias e usuários relataram a relevância pessoal que tinha o convívio naquele espaço. A convivência ali concentrava boa parte das experiências vividas por todas as envolvidas. Não parece se tratar, pois, de um espaço qualquer onde se trabalhava ou onde se ia "estudar", mas de um espaço especialmente importante na vida das pessoas que dele participavam.

O uso de uniformes pelas usuárias e usuários, a organização em salas para a realização de atividades e a convergência entre o calendário escolar e o calendário de funcionamento da Comunidade (férias, feriados emendados, dias festivos) são aspectos que a assemelhavam às escolas. Entretanto, o tipo de atividades desenvolvidas a distanciavam da referência que convencionalmente damos ao termo "escola". Não havia terminalidade, não havia organização em ciclos progressivos, não havia um projeto pedagógico. Se é verdade que esses fatos parecem mostrar que a Comunidade da Figueira não se confundia com qualquer espaço escolar, não é menos verdade que o sistema educacional de ensino no município parecia mostrar o lugar marginal que nele ocupava.

O município contava com monitoras de estudantes com deficiência nas escolas comuns. Uma dessas escolas possuía uma sala de recursos para o atendimento educacional especializado de muitos desses usuários no contra-turno das escolas comuns. O município conta também com uma escola especial que funciona como espaço de atendimento educacional 
especializado, no contra-turno, para aqueles usuários com deficiência que não frequentavam a sala de recursos. Essa escola especial funcionava também como único espaço educacional para aqueles estudantes com deficiência que não frequentavam a escola comum. A Comunidade era frequentada por pessoas com deficiência sem qualquer experiência escolar, mas também por quem já frequentara a escola, seja a comum, seja a especial, e que encontraram na Figueira, pelo próprio estilo da exclusão educacional no município, um espaço para chamar de "escola".

São justamente essas usuárias e usuários, aquelas e aqueles que já haviam tido uma experiência educacional que chamavam a Comunidade da Figueira de "escola", mas também usavam os termos "professora" ou "professoras" para se referir às monitoras, ou mesmo à diretora. Embora as responsáveis e muitas usuárias e usuários não caracterizassem a Comunidade como um espaço educacional, mas sim de acolhimento, as responsáveis, e mesmo as monitoras, costumavam se referir aos usuários usando o termo "alunos", mas, sobretudo, "meninos".

\section{"Meninos" e "professoras": uso equivocado ou (politicamente) correto?}

Como vimos na seção anterior, embora a Comunidade da Figueira ocupe um lugar na educação de pessoas com deficiência no município, esse lugar se justifica justamente por não ser um espaço escolar. Mesmo não sendo um espaço escolar, encontramos suas responsáveis e suas usuárias e usuários recorrendo a nomes de papéis sociais que encontramos vinculados aos espaços escolares, no caso "meninos", mas também "alunos", e "professoras", para se referir aos seus papéis sociais na Comunidade. Estariam nomeando os papéis de usuários e usuárias e de monitoras equivocadamente? Estamos frente a um tipo especial de problema de correspondência entre linguagem e mundo (social), mas não do tipo que a filosofia da linguagem, fundamentada na lógica, procura "resolver" recorrendo à distinção entre sentido e referência. Na perspectiva hegemônica da filosofia da linguagem não interessa uma realidade social particular ou o uso concreto da linguagem comum e sim o caráter lógico da relação entre linguagem e significado. O problema da representação educacional na Comunidade da Figueira foge à lógica filosófica. O problema não é a falta de correspondência 
entre uma realidade extralinguística e a referência que usuárias e responsáveis têm para si de uns e outros, pois, essa realidade é social e não física. Qual realidade física define o critério de verdade quando uma usuária chama uma monitora de "professora"?

O problema representacional na Figueira - de uma ambiguidade entre usos de designações de escola e as práticas não escolares - não se resolve concluindo que não há correspondência entre a realidade da Figueira e a representação que desta fazem responsáveis, usuários e usuárias. Essa questão de correspondência seria relevante se tomássemos as nomeações como se fossem etiquetas de preço, a análise do uso da linguagem como um leitor ótico e o nosso papel como o de operadores de caixa que estranham a não-correspondência entre etiqueta e produto. Uma abordagem semântica da correspondência apresenta limitações éticas para a pesquisa, pois pressupõe uma incapacidade das pessoas de serem responsáveis pelas escolhas dos termos que usam. Mas nós partimos da pragmática social e consideramos a responsabilidade das pessoas pelo que dizem (Rajagopalan, 1999, 2003).

Nossas observações sobre o uso dos termos "meninos" e "professoras" se deram durante as atividades de um projeto de extensão universitária que tinha como objetivo contribuir com as ações de cuidado e promoção de contato desenvolvidas pela Comunidade entre pessoas com e sem deficiência. Embora, como mencionei, o uso da designação "meninos" remeta a uma realidade escolar, o avançar da idade de muitas usuárias e usuários parece solicitar de algumas responsáveis uma correspondência mais verossímil. Sobretudo quando confrontadas com outsiders como nós. Assim, uma monitora, a diretora e a psicóloga, nos primeiros encontros na Figueira, vez por outra, explicavam que utilizavam o termo "meninos" como uma demonstração de carinho, como um costume já sedimentado justificado pelas suas atitudes infantis e como uma forma de reconhecer sua "idade mental", motivos estes quase sempre expostos de forma relacionada. Para as responsáveis, as usuárias e usuários são "meninos" porque se comportam de forma infantilizada. Uma alegria espontânea revelada por alguma brincadeira despropositada, um enfado repentino relacionado a um sentimento de ciúme são os comportamentos mais comumente identificados como infantis. Para a psicóloga, essa infantilidade está associada, ainda, à "idade mental" - como explicou certa vez ao dizer que Dona Cacá "tem mais de quarenta, mas tem a idade mental de uma criança pequena". 
Cabe destacar que se trata de uma explicação sem intenção de menosprezar adultos. Entretanto, o termo "idade mental", se não menospreza, pelo menos ordena de forma hierarquizada as relações entre responsáveis e usuárias. Assim, comportamentos semelhantes por parte das responsáveis como, por exemplo, ter a iniciativa de pular e cantar - o que poderia ser caracterizado como um comportamento infantil não justificam o uso do termo "meninas" para se referir às monitoras. Há, pois, uma diferença entre a forma como as atitudes infantis são representadas. Uma diferença que é hierarquizante pois, se a "idade mental" explica as atitudes infantis das usuárias e usuários, não explica as atitudes infantis das responsáveis. Não há nada de errado nas atitudes infantis, mas se a "idade mental" explica as atitudes de usuários e usuárias e não as das responsáveis, temos uma hierarquia que organiza as relações de poder no interior da Comunidade.

Essa correspondência entre "idade mental" e "meninos" nos incomodou bastante quando começamos a frequentar a Comunidade. Ainda mais porque as estudantes do curso de pedagogia que participavam da equipe de extensão passaram a usar o termo tanto na Figueira como nos encontros de orientação. Mas o uso do termo "meninos" pelas estudantes não tinha relação com a representação da "idade mental" de usuários e usuárias da Comunidade. Utilizavam o termo nos encontros de orientação para se apresentarem a si próprias como pessoas com maior autoridade para lidar com atividades pedagógicas nas salas. $\mathrm{Na}$ Comunidade, por outro lado, utilizavam o termo "meninos" de forma a simpatizar e se identificar com as monitoras. É nesse contexto dos primeiros meses dos trabalhos de extensão que introduzimos os termos "usuárias" e "usuários" como nomeação quando dialogávamos com as monitoras a respeito dos usuários e usuárias da Comunidade. Nossa escolha pelo termo foi consciente. Com a expressão "usuários" e "usuárias" nosso propósito era, ao mesmo tempo, marcar linguisticamente um lugar próprio dos integrantes do projeto durante nossas estadias naquele espaço e criar um contraponto ao uso de "meninos" pelas monitoras, permitindo gerar reflexões de nossa parte e da parte das responsáveis pela Comunidade sobre aquela relação que estava sendo proposta por nós e sobre a nossa participação naquela realidade que passávamos a integrar de nosso modo. 
A nossa escolha contribuiu para reconhecer nossa distância em relação ao trabalho que era realizado na Comunidade, assim como, para avaliar nossas possibilidades de intervenção e reavaliar nossas ações naquele espaço. Mas no início as estudantes de pedagogia resistiam ao uso do termo "usuários", pois, para elas, remetia a um universo de instituições voltadas para psicóticos. Já as estudantes de serviço social usaram o termo sem constrangimentos, pois na profissão na qual estavam se formando é corrente o seu uso: usuários de políticas sociais.

Também passamos a utilizar o epíteto "dona" ou "senhor" antes do nome próprio de usuários e usuárias que eram mais velhos do que nós. Como forma de reforçar nossa posição quanto à tese da "idade mental" e de reconhecer a validade das formas de tratamento respeitosas para com os mais velhos. Para Dona Cacá, tal tratamento no início resultou em risos da monitora de sua sala, mas também da própria Dona Cacá, que achava graça nesse tipo de tratamento. Estes risos foram o melhor indício de que os contrapontos estavam surtindo efeito.

Para nos posicionar em relação ao uso do termo "professoras" pelas usuárias e usuários, escolhemos o termo "monitoras", de uso comum entre as responsáveis pela Comunidade, sobretudo pela diretora e a psicóloga. Esse uso não foi efeito de uma reflexão tão consciente quanto a que levou a nossa escolha pelos termos "usuárias" e "usuários". Inicialmente, as usuárias e usuários não compreendiam exatamente a quem nos referíamos quando perguntávamos "Maria é a monitora de sua sala?". Uma delas achou engraçado o uso do termo "monitora". Entretanto, ao introduzir esse termo na Comunidade, contribuímos para certos efeitos emancipatórios. As usuárias incorporaram o termo "monitoras" como sinônimo de "professoras", como mostrou a celebração do dia dos professores, no ano de 2012, quando um grupo de usuárias presenteou as monitoras, a secretária, a psicóloga e a diretora, com uma homenagem. Deram lembrancinhas e colaram cartazes em lugares de circulação onde se lia "Parabéns às monitoras da Figueira" e "Feliz dia do professor". Todas se emocionaram. O planejamento da homenagem correu por conta de duas das usuárias que aproveitavam o tempo livre fora das salas para delegar responsabilidades e articular com outras colegas o que teria que ser feito. Recolheram dinheiro para as lembrancinhas, confeccionaram os cartazes com outra colega e organizaram o cerimonial da homenagem apresentando as colegas 
antes de estas darem seus depoimentos agradecidos e emocionados. Essa comemoração, inédita na Comunidade, mostra um posicionamento bem claro por parte das usuárias envolvidas, e o reconhecimento do uso oficial "monitoras" possibilitou a criação de um contexto que interpela explicitamente as responsáveis na condição de professoras.

\section{A linguagem politicamente correta: do abuso ao uso}

Rajagopalan (2000) pergunta pelo fenômeno da repulsa à linguagem politicamente correta que parece estar disseminado tanto na esquerda como na direita. Em vez de considerar a expressão "linguagem politicamente correta" como acusatória, Rajagopalan se pergunta pelas representações que tornam politicamente correto o uso acusatório da expressão. Assim, encontramos a crença na arbitrariedade e independência da linguagem em relação às coisas que representamos com ela. Uma tese homóloga é defendida por Becker (2007), que recomenda não julgar a acuidade de determinada representação da sociedade mas, partindo do pressuposto de que toda representação tem uma finalidade para a qual ela foi construída coletivamente, perguntar sobre as condições que fazem essa representação adequada (um mapa de ruas não é imperfeito porque não mostra os morros que os pedestres têm que subir, é perfeito para indicar por onde se deve ir de carro). Ambos nos colocam a necessidade de nos deslocar do ponto de vista a partir do qual julgamos a validade das representações como deploráveis ou incorretas, especialmente quando acreditamos, paradoxalmente, que esse julgamento não é moral, ou político. Como se julgar uma representação como errada ou incorreta fosse um (meta)ato, acima da moral, acima da adequação. Ao contrário, é possível desconstruir ou reconstruir os valores, os fatos e as relações sociais que precedem as representações. Trata-se de aceitar, por um lado, que toda forma de representação é adequada a determinadas condições sociais de feitura e uso (Becker, 2007) e, por outro, que toda representação é política, pois é uma escolha dentre representações possíveis e, quase sempre, conflitantes entre si (Rajagopalan, 2003).

Considerando o caso das designações, em vez de procurar responder, para cada caso em questão, se o seu uso corresponde ou não 
corresponde, em cada caso, o uso de determinada designação. O contexto de uso da linguagem não tem existência independente das relações sociais e a linguagem é um elemento constitutivo dessas relações. Não somente os termos que usamos para nos referir ao que é preferível, mas também aqueles com os quais nos referimos ao que existe-como é o caso das designações - parecem participar da mesma dinâmica de avaliação moral vinculada aos contextos de uso. Devemos considerar, pois, o contexto das relações entre as pessoas e o contexto da vida social para saber como a escolha de termos se sustenta e por que esses termos são usados e não outros. Para Mey (2003), a dinâmica de "(des) ambiguação" no uso da linguagem ocorre de modo que as pessoas se expressam de uma forma que os usos correspondem ao contexto mas também o contexto é recriado de forma a corresponder aos usos. O uso de determinada designação é uma escolha por certa correspondência com a realidade social, uma escolha por um certo contexto.

Para Rajagopalan (2000), "intervir na linguagem significa intervir no mundo". Após sete meses da realização do projeto, insistimos no uso dos termos "usuárias", "usuários" e "monitoras", mas com reservas. Continuamos a rejeitar o uso do termo "meninos", mas passamos a avaliar nos nossos encontros de orientação a possibilidade de adotar no nosso vocabulário os termos "alunos" e "alunas", e assim o fizemos, pois consideramos que seria benéfico acompanhar a Comunidade no uso de termos de escola para enfatizar e participar nesse contexto criado para a Figueira e explicitar seu lugar no sistema municipal de ensino. Qual é esse contexto? Como intervir nele? Como é socialmente constituído o uso dos termos "meninos" e "professoras" na Comunidade da Figueira? Como constituir socialmente o uso de outros termos? Essas são as questões que procuramos responder nas atividades de extensão que realizamos. Se, na distribuição da educação de pessoas com deficiência no sistema de ensino municipal, encontramos a Comunidade à margem desse sistema, ao considerarmos os termos utilizados para distinguir os papéis sociais na Comunidade, encontramos também uma forma de resistência.

Recebido em fevereiro de 2014

Aprovado em fevereiro de 2015

E-mail: ubiratan.vieira@uffs.edu.br 


\section{Referências bibliográficas}

BECKer, Howard S. 2007. Telling about society. Chicago: University of Chicago Press.

DAvis, John M. 2006. Disability Studies as Ethnographic Research and Text: Research Strategies and Roles for Promoting Social Change? In: Barton, Len (org.). Overcoming Disabling Barriers. London/ New York: Routledge.

Diniz, Débora, Medeiros, Marcelo \& SQuinca, Flávia. 2007. Reflexões sobre a versão em Português da Classificação Internacional de Funcionalidade, Deficiência e Saúde. Cadernos de Saúde Pública. v. 23: $2507-2510$.

Hymes, Dell. 1984. Vers la compétence de communication. Paris: HatierCredif.

MeY, Jacob L. 1994. How to do good things with words: a social pragmatics for survival. Pragmatics. v. 4, n. 2: 239-263.

2003. Context and (dis)ambiguity: a pragmatic view. Journal of Pragmatics. v. 35, n. 3: 331-347.

. 2010. Current issues in societal pragmatics. Cadernos de Linguagem e Sociedade. v. 11, n. 1: 195-218.

Rajagopalan, Kanavillil. 1999. Cognitive versus social aspects of pragmatic meaning: on the importance of identifying the subject as an ethical agent. ALFA. v. 43: 135-144.

2000. Sobre o porquê de tanto ódio contra a linguagem "politicamente correta". In: Heronides Moura \& Fábio Lopes da Silva (orgs.). O direito à fala. 2. ed., rev. Florianópolis: Editora Insular. 2003. Por uma linguística crítica: linguagem, identidade e a questão ética. São Paulo: Parábola.

.2010. Nova pragmática: fases e feições de um fazer. São Paulo: Parábola.

VieIRA, Ubiratan. 2013. Descontinuidades da inclusão e da exclusão na educação de pessoas com deficiência no Brasil. In: PINTo, Joana Plaza \& Fabrício, Branca Falabella (Orgs.). Exclusão Social e Microrresistências. Goiânia: Cânone Editorial.

WHO. 2002. Towards a common language for functioning, disability and health: ICF. Geneva: World Health Organization. Disponível em: $<$ http://www.who.int/classifications/icf/training/icfbeginnersguide. $\mathrm{pd}>$. Acessado em 11/08/2014 